\title{
Galactinol Synthase Gene Expression in Melon
}

\author{
Gayle M. Volk, ${ }^{1}$ Edith E. Haritatos, Robert Turgeon \\ Department of Plant Biology, Cornell University, Ithaca, NY 14853
}

\begin{abstract}
ADDitional INDEX WORDs. raffinose family oligosaccharides, Cucumis melo, sugars
AbSTRACt. Raffinose family oligosaccharides (RFOs) perform several physiological functions in plants. In addition to accumulating during seed formation, raffinose and stachyose are translocated in the phloem and may accumulate in response to low temperatures, drought, or salt stress. Although the synthesis of galactinol, as mediated by galactinol synthase (GAS), is the first committed step in RFO formation, its expression patterns are poorly understood in most species. We have cloned and characterized the expression of two galactinol synthase gene family members in melon (Cucumis melo L. Cantalupensis Group). Both $C m G A S 1$ and $C m G A S 2$ are highly expressed in mature leaves. Galactinol synthase transcription in leaves was not upregulated by either water or low temperature stresses. Transcripts of $C m G A S 1$ were present in developing melon seeds at a time coincident with the formation of raffinose and stachyose. Based on the GAS expression and RFO accumulation patterns, we propose that RFOs in melon function in carbon translocation and seed desiccation tolerance.
\end{abstract}

The synthesis of raffinose family oligosaccharides (RFOs) has been implicated in many developmental and physiological processes in plants. The enzyme galactinol synthase (GAS; UDPgalactose : inositol galactosyltransferase) catalyzes the formation of galactinol from myo-inositol and UDP-galactose. This galactinol serves as a galactose donor for raffinose and stachyose synthesis.

Members of the Cucurbitaceae, Scrophulariaceae, Labiatae, Celastraceae and Oleaceae, and probably other families, translocate significant quantities of RFOs in the phloem (Turgeon et al., 2001; Zimmerman and Ziegler, 1975). These plants have numerous plasmodesmata between the specialized companion cells (intermediary cells, ICs) and surrounding mesophyll layers that are thought to permit the passage of sucrose from the mesophyll cells into the ICs, where it is then converted to galactinol and RFOs before transport (Haritatos et al., 1996).

Raffinose and stachyose are also synthesized in many orthodox (desiccation tolerant) seeds. They may provide protection to membranes that surround cellular compartments, preventing sucrose crystallization in vegetative tissues destined to undergo severe dehydration, for example in Xerosicyos, Ramonda, Haverlea, and Boea (Albini et al., 1999; Caffrey et al., 1988; Corbineau et al., 2000; Muller et al., 1997; Peterbauer and Richter, 2001).

Many species make RFOs in response to low temperature stress conditions. RFOs may serve as carbon storage pools in low temperature tolerant plants since the enzymes that catalyze RFO formation are thought to be less sensitive to low temperatures than those which catalyze the formation of starch (Bachmann et al., 1994). It has been shown that GAS transcripts accumulate in vegetative tissues of Arabidopsis thaliana and in some seeds after exposure to low temperatures (Liu et al., 1998; Peterbauer and Richter, 2001). In addition, GAS enzyme activity is higher in winter-hardy than in noncold-hardy alfalfa crowns during low temperature acclimation (Castonguay and Nadeau, 1998). Furthermore, stachyose accumulates in the vacuoles of parenchyma cells of Stachys siebaldii tubers

Received for publication: 12 Feb. 2002. Accepted for publication 22 Oct. 2002 Use of trade names does not imply endorsement of products named or criticism of ones not mentioned. The nucleotide sequences reported in this paper have been submitted to the GenBank nucleotide sequence database under the accession numbers AY077641 and AY077642. We thank Phillip Kerr (DuPont) for kindly providing the zucchini leaf GAS cDNA, Adam Henk for assistance with phylogenetic analyses, and Brian Ayre for reviewing this manuscript. This work was funded in part by USDA Competitive Grant NYC-184528 to RT.

${ }^{1}$ Plant Germplasm Preservation Research Unit, National Center for Genetic Resources Preservation, USDA-ARS, Ft. Collins, CO 80521; to whom reprint requests should be addressed. and ajugose (a hexasaccharide RFO) accumulates in the mesophyll cells of Ajuga reptans after exposure to low temperatures (Bachmann and Keller, 1995; Sprenger and Keller, 2000). These acclimation responses may be critical for the survival of low temperature tolerant species.

Although the presence of RFOs has been documented in a variety of systems, there are few studies demonstrating the expression of the GAS genes. Sprenger and Keller (2000) published a study that described the expression patterns of two galactinol synthase genes, GolS-1 and GolS-2, in Ajuga reptans. Ajuga is a frost-hardy evergreen labiate that both accumulates and translocates RFOs. The gene, GolS- 1 was primarily expressed in the mesophyll in response to low temperatures while GolS-2 was expressed in intermediary cells and most likely catalyzes the formation of RFOs destined for translocation. The Arabidopsis GAS genes AtGolS1 and AtGolS2 are expressed in response to drought and salt stress while AtGolS3 accumulates in response to low temperature stress (Taji et al., 2002). The expression patterns of other Arabidopsis GAS genes have not been characterized.

We have cloned two GAS genes in melon (Cucumis melo L. Cantalupensis Group). One gene, $C m G A S 1$, is highly homologous to the zucchini $C p G A S 1$ gene identified by Kerr et al. (1993). A CmGAS1 promoter-gusA fusion was made and used to transform Arabidopsis and tobacco plants. In these transgenic plants, GUS expression localized to the smallest veins of mature Arabidopsis and tobacco leaves (Haritatos et al., 2000). Although galactinol is not normally synthesized in wild-type tobacco leaves, stain localized to the companion cells and sieve elements in the minor veins (Haritatos et al., 2000), indicating that the CmGASl promoter drives veinspecific gene expression. There are no previous reports documenting the expression pattern of the second melon GAS gene, CmGAS2.

In melon, raffinose and stachyose serve as phloem translocation sugars and also accumulate in maturing seeds. Other functions of RFOs in melon have not been documented. We have used RNA blots and RT-PCR techniques to characterize the mRNA expression patterns of the CmGAS1 and CmGAS2 genes in melon.

\section{Materials and Methods}

Plant material. Melon plants (Cucumis melo cv. Hale's Best Jumbo, Burpee/Ball Seed Co., West Chicago Ill.) were grown in 15$\mathrm{cm}$-diameter clay pots with potting soil in a growth chamber (CEL 37-14; Sherer-Gillette/Revco/Lindberg, Asheville, N.C.) with 425 $\mathrm{mmol} \cdot \mathrm{m}^{-2} \cdot \mathrm{s}^{-1}$ illumination provided by $160-\mathrm{W}$ VHO cool white fluorescent bulbs. A 16-h/8-h light/dark photoperiod and $27{ }^{\circ} \mathrm{C} / 22$ ${ }^{\circ} \mathrm{C}$ light/dark temperatures were provided. 
Table 1. Sequences of gene-specific primers used for PCR.

\begin{tabular}{ll}
\hline \hline Primer & Sequence \\
\hline 5'RACE CmGAS1 & 5'-GTAGCGCTGCACAATAGTGGAC-3' \\
3'RACE CmGAS1 & 5'-CTTGAGACTTGCAAGGCCACTACT-3'
\end{tabular}

Replicate pots of 3 -week-old melon plants were treated to $8{ }^{\circ} \mathrm{C}$ dark periods for 1, 2, or 3 consecutive days. Entire plants were harvested and individual organs were frozen in liquid nitrogen either 2 or $8 \mathrm{~h}$ after the low temperature treatment. Controls were not subjected to $8^{\circ} \mathrm{C}$ night temperatures.

In water stress studies, water was withheld from 3-week-old melon plants for 4, 5, 6, 7, or $8 \mathrm{~d}$. Two replicate plants were harvested midday after the water-stress period. Control plants were wellwatered throughout the experiment.

Field melon plants were started in growth chambers, hardened in cold frames, and transplanted to black plastic mulch covered rows approximately three weeks after germination. Flowering occurred two weeks later, at which time female flowers were hand-pollinated and tagged. Fruit were thinned to two per plant. Five melons were harvested at 3- to 6-d intervals (15 times during fruit development). The largest and smallest melons were discarded and sugars were extracted from 50-seed subsamples of the remaining three melons at each time point as described by Turgeon et al. (1993). After ion exchange, the extract was dried, dissolved in water, and filtered before separation by high-performance liquid chromatography

Table 2. GAS GenBank accessions used for phylogenetic analyses.

\begin{tabular}{|c|c|c|c|c|}
\hline Gene & $\begin{array}{l}\text { Common } \\
\text { name }\end{array}$ & $\begin{array}{c}\text { DNA } \\
\text { GenBank No. }\end{array}$ & $\begin{array}{c}\text { Protein } \\
\text { GenBank No. }\end{array}$ & Expression \\
\hline \multirow[t]{8}{*}{$\overline{\text { AtGolS1 }}$} & Arabidopsis & AC002337 & AAB63818 & Drought, salt \\
\hline & & NM_130286.1 & NP_182240.1 & \\
\hline & & A'̄056139 & AĀL07218.1 & \\
\hline & & AY091426 & AAM14365.1 & \\
\hline & & AB062848 & BAB78530.1 & \\
\hline & & AC007236 & AAM15468.1 & \\
\hline & & AC002337 & AAB63818.1 & \\
\hline & & AY085006 & AAM61564.1 & \\
\hline \multirow[t]{6}{*}{ AtGolS2 } & Arabidopsis & NM_104537 & NP_176053.1 & Drought, salt \\
\hline & & AY058238 & AAL 15412.1 & \\
\hline & & AY050410 & AAK91426.1 & \\
\hline & & АB062849 & BAB78531.1 & \\
\hline & & AC009323 & AAG09103.1 & \\
\hline & & AF412094 & AAL06547.1 & \\
\hline \multirow[t]{7}{*}{ AtGols3 } & Arabidopsis & AC003970 & AAC33195.1 & Cold \\
\hline & & AF370546 & AAK48973.1 & \\
\hline & & NM_100805 & NP_172406.1 & \\
\hline & & AY081452 & AAM10014.1 & \\
\hline & & AF370546 & AAK48973.1 & \\
\hline & & AB062850 & BAB78532.1 & \\
\hline & & AC003970 & AAC33195.1 & \\
\hline \multirow[t]{2}{*}{ AtGolS4 } & Arabidopsis & NM_104734 & NP_176250.1 & \\
\hline & & AC002292 & AAB71970.1 & \\
\hline \multirow[t]{3}{*}{ AtGolS5 } & Arabidopsis & AB005244.2 & BAB10052.1 & Siliques \\
\hline & & AB000015 & & \\
\hline & & NM_122284 & NP_197768.1 & \\
\hline \multirow[t]{3}{*}{ AtGols6 } & Arabidopsis & AL049171 & CAB38954.1 & \\
\hline & & AL161564 & CAB79480.1 & \\
\hline & & NC_003075.1 & NP_194355 & \\
\hline \multirow[t]{2}{*}{ AtGols7 } & Arabidopsis & AC004473 & AAC24075.1 & \\
\hline & & NM_104732 & NP_176248.1 & \\
\hline Brassica & Brassica & AF106954 & AAD26116.1 & \\
\hline Pisum & Pea & AJ243815 & CAB51130.1 & Embryo \\
\hline ArGolS1 & Ajuga reptans & AJ237693 & CAB51533.1 & Source lvs, cold \\
\hline ArGolS2 & Ajuga reptans & AJ237694 & CAB51534.1 & Sink leaves \\
\hline Vitis & Grape & AF178569 & AAD55726.1 & \\
\hline Oryza & Rice & D26537 & BAA05538.1 & Water stress \\
\hline$C p G A S 1$ & Zuchinni & patent & & \\
\hline Glycine & Soybean & patent & & Seeds \\
\hline CmGASI & Melon & AY077642 & AAL78687.1 & Leaves, seeds \\
\hline CmGAS2 & Melon & AY077641 & AAL78686.1 & Leaves \\
\hline Thellungiella & Thellungiella & AF499723 & AAM19710.1 & \\
\hline At NM_122802 & Arabidopsis & NM_122802 & NP_56816.1 & \\
\hline Lycopersicom & Tomato & AF311943 & AAL26804.1 & Seeds \\
\hline
\end{tabular}


(HPLC) using a Waters (Milford, Mass.) model 510 pump, a Waters SugarPak1 column at $90{ }^{\circ} \mathrm{C}$, and a Waters model 410 differential refractometer. Calcium disodium EDTA $\left(50 \mathrm{mg} \cdot \mathrm{L}^{-1}\right)$ was the solvent (Turgeon et al., 1993).

NuCleic ACID EXTRACTION. Genomic DNA was extracted from dark-grown melon seedlings as described by Haritatos et al. (2000). Ten-microgram samples of melon genomic DNA were digested with BamHI, EcoRI, EcoRV, HindIII, KpnI, SstI, or XhoI restriction enzymes (Gibco BRL, Life Technologies, Gaithersburg, Md.). Digested DNA was separated on a 1\% agarose gel and transferred to nylon membranes (GeneScreen Plus, DuPont-New England Nuclear, Boston).

Total RNA was extracted by a modified Kirby phenol extraction procedure (Goldsbrough et al., 1986; Kirby and Cook, 1967). Poly $(\mathrm{A})^{+}$RNA was separated from total RNA using an oligo(dT)cellulose batch-binding method (Stratagene, LaJolla, Calif.). Ten micrograms of total RNA were denatured with glyoxyl and electrophoresed on a $1 \%$ agarose, $0.01 \mathrm{~m}$ sodium phosphate, $\mathrm{pH} 7$ gel containing ethidium bromide (McMaster and Carmichael, 1977).

LibRARY CONSTRUCTION. A partial melon genomic library was generated by partially digesting genomic melon DNA $(100 \mu \mathrm{g})$ with MboI, fractionated on a sodium chloride gradient, and separated by agarose gel electrophoresis. DNA from the 9 to $23 \mathrm{kB}$ bands on the gel was ethanol precipitated, ligated to BamHI restricted arms of the bacteriophage $\lambda$ GEM11, and packaged with Packagene Lambda DNA Packaging System (Promega, Madison, Wis.). The library (400,000 phage) was screened by hybridization to a radiolabeled probe using a 784 bp HindIII open reading frame of the CpGASI cDNA [CpGAS1 probe was provided by DuPont (Kerr et al., 1993)]. Phage were plaque-purified, subcloned using SstI restriction sites into pBluescript II KS+ (Stratagene), and maintained in DH5a bacteria. A melon subgenomic library was constructed to clone a specific band that the CpGAS1 probe binds to on a Southern blot as described by Haritatos et al. (2000).

RADIOLABELED PROBES AND HYBRIDIZATION. The $C p G A S$ probe was made from a 784 bp HindIII fragment of the CpGAS1 cDNA. The CmGAS1 gene specific probes were made from a cloned $186 \mathrm{bp}$ fragment between two adjacent HincII restriction sites in the $3^{\prime}$ untranslated region of the melon CmGAS1 gene. The SspI site in the 3 ' untranslated region and an Xbal site within the multiple cloning site of a subcloned $C m G A S 2$ gene fragment were used to generate a 302 bp fragment from which $C m G A S 2$ gene specific probes were made.

Fragments of DNA were labeled with $\alpha^{32} \mathrm{P}-\mathrm{dCTP}$ (DuPont-New England Nuclear) using a randomly primed DNA-labeling kit (Boehringer Mannheim, Indianapolis, Ind., USA) and unincorporated nucleotides were removed by passage over a sephadex G50 column (Sigma, St. Louis) before standard hybridization protocols (Sambrook et al., 1989).

PCR AND CLONING. To confirm expression results obtained by northern blotting, poly $(\mathrm{A})+\mathrm{RNA}$ was reverse-transcribed and amplified using CmGAS1 gene-specific primers following a RACE protocol (Clontech, Palo Alto, Calif.) (Table 1). The RACE kit AP1 adapters were ligated to cDNA made from $1 \mu \mathrm{g}$ of poly $(\mathrm{A})^{+} \mathrm{RNA}$ extracted from melon seeds $39 \mathrm{~d}$ after pollination (DAP). Polymerase chain reaction (PCR) solutions of $50 \mu \mathrm{L}$ included $5 \mu \mathrm{L} 10 \mathrm{x}$ PCR buffer (Perkin-Elmer, Foster City, Calif.), $1 \mu \mathrm{L} 10$ mm dNTPs (Clontech), $1 \mu \mathrm{L}$ each of $10 \mu \mathrm{M}$ AP1 primer and gene specific primers (Table 1), and 1 U AmpliTaq DNA polymerase (PerkinElmer). Either 0.05 or $0.01 \mu \mathrm{g}$ of cDNA template was included in PCR reactions. Hot-start PCR amplification was performed in an Amplitron II thermocycler(Barnstead/Thermolyne Corp., Dubuque,
Iowa) for 30 cycles with $30 \mathrm{~s}$ at $94^{\circ} \mathrm{C}$ and $4 \mathrm{~min}$ at $68^{\circ} \mathrm{C}$ or for 30 cycles with $94^{\circ} \mathrm{C}$ for $30 \mathrm{~s}, 60^{\circ} \mathrm{C}$ for $30 \mathrm{~s}$, and $68^{\circ} \mathrm{C}$ for $4 \mathrm{~min}$. Amplification products were separated on a $1 \%$ agarose gel, blotted to membrane, and hybridized with the $784 \mathrm{bp}$ HindIII fragment of the $C p G A S 1$ probe. Bands that hybridized with the probe were removed from a low-melt agarose gel and purified using Clontech's GENO-BIND matrix. Purified products were reamplified by PCR using the same conditions. PCR products were cloned using the TA Cloning Kit (Invitrogen, San Diego). Inserts from colonies that hybridized to the conserved GAS probe were sequenced.

Phylogenetic analyses. GAS gene family members were identified using BLAST searches of the NCBI nucleotide database (Table 2). Alignments were performed using predicted cDNA sequences and are available at www.ars-grin.gov/ncgrp/publications.htm. Hypervariable regions (the first 142 nucleotides according to the alignment) were removed. The remaining homologous sequences were used for parsimony analysis and a collapsed, bootstrapped (10,000 replicates) tree was generated using PAUP set to retain groups with a frequency $>50 \%$ (Swofford, 2002).

\section{Results}

Galactinol SYNThase genes. A conserved GAS cDNA probe ( $C p G A S 1$ probe) from zucchini was used to identify homologous sequences in melon. Southern blots were made from digested genomic melon DNA and hybridized with the $C p G A S 1$ probe (Kerr et al., 1993). For most restriction enzymes, one band hybridized strongly with the conserved GAS probe and several minor bands

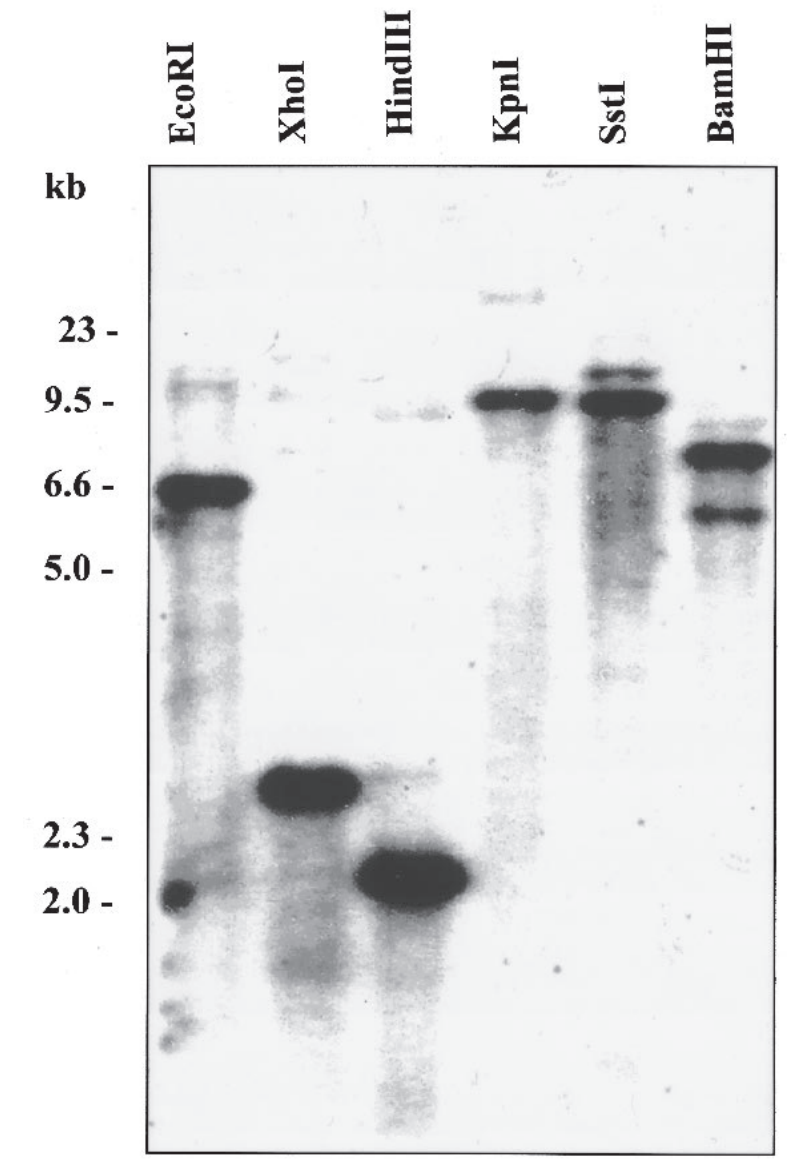

Fig. 1. DNA gel blot analysis of genomic melon DNA (10 $\mu$ g) digested with EcoRI, XhoI, HindIII, KpnI, SstI, or BamHI restriction enzymes. Blot was hybridized with a radiolabeled conserved $C p G A S 1$ probe. 


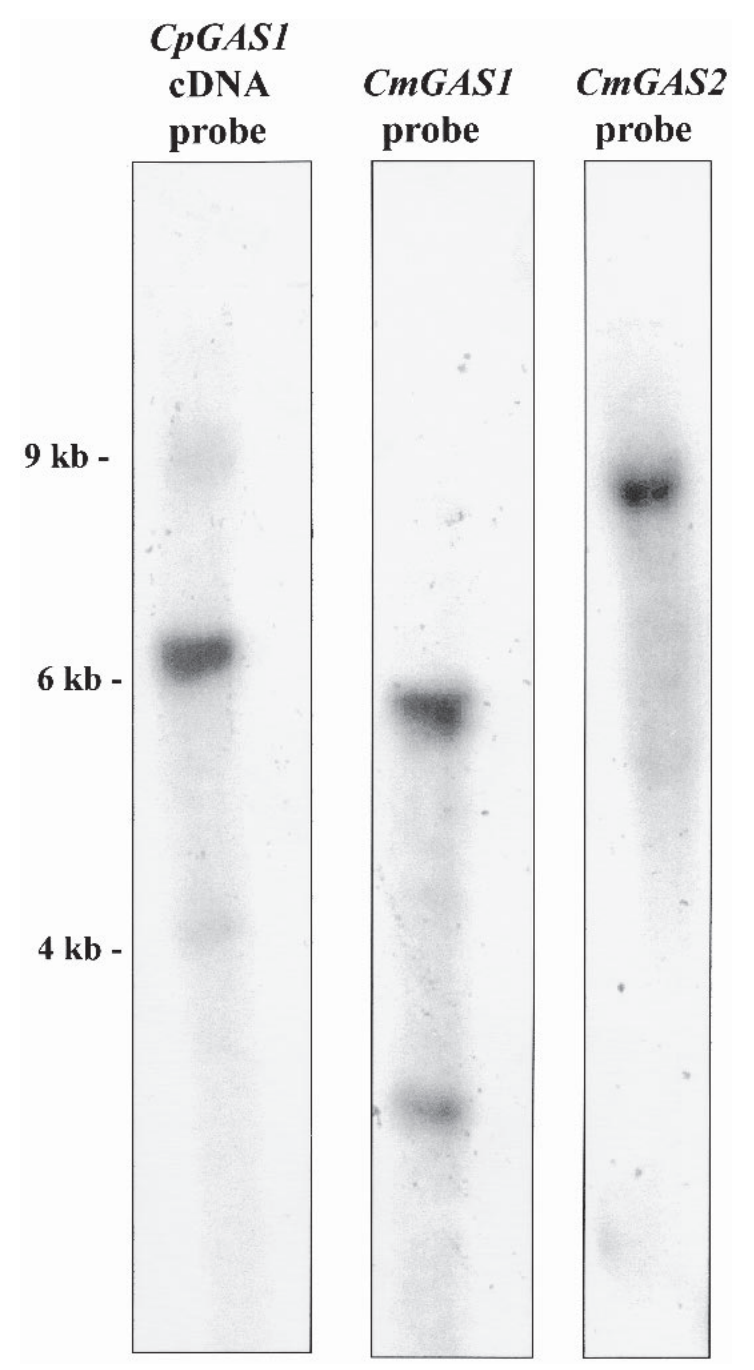

Fig. 2. Southern blot analysis of genomic melon DNA $(10 \mathrm{mg})$ digested with EcoRI and probed with a radiolabeled conserved GAS ( $C p G A S 1$ probe), or gene specific CmGAS1, or CmGAS2 probes.

were apparent (Fig. 1). The band that hybridized most strongly $(\approx 6.6$ $\mathrm{kb})$ on the EcoRI digrest is highly homologous to the CpGASI probe. Two of the DNA fragments that hybridized to the conserved GAS probe on EcoRI-restricted DNA were cloned (6.6 and $9 \mathrm{~kb})$.

The melon GAS1 gene ( $\mathrm{Cm} G A S 1)$ and promoter were subcloned from a subgenomic library made from a 6-kb EcoRI restriction fragment of DNA, as described by Haritatos et al. (2000). Gene specific probes (from the 3' untranslated region) from this clone hybridize to the $6.6 \mathrm{~kb}$ band on Southern blots made from EcoRIdigested genomic melon DNA (Fig. 2) and did not cross-hybridize with $C m G A S 2$ plasmid DNA (data not shown). Sequencing revealed that three introns, of lengths $155 \mathrm{bp}, 482 \mathrm{bp}$, and $132 \mathrm{bp}$ are present in the CmGAS1 gene. Four exons of lengths $315 \mathrm{bp}, 324 \mathrm{bp}$, $135 \mathrm{bp}$, and $219 \mathrm{bp}$ probably encode a pu-

A. $C m G A S 1$

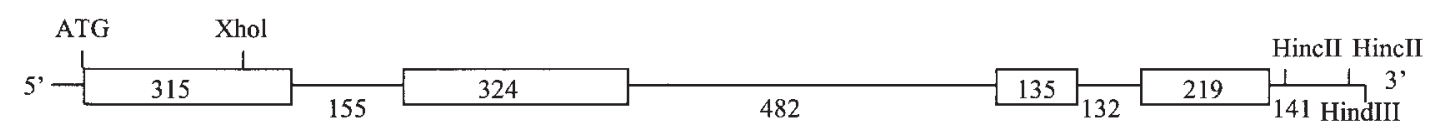

tative protein 331 amino acids long (Fig. B. CmGAS2 $3 \mathrm{~A})$.

The melon GAS2 gene (CmGAS2) was subcloned from a $\lambda$
GEM11 bacteriophage library made from fractionated genomic DNA partially digested with MboI. The 302 bp CmGAS2 gene specific probe hybridized with the $9 \mathrm{~kb}$ band on Southern blots made from EcoRI-digested genomic melon DNA (Fig. 2) and did not cross-hybridize with $C m G A S 1$ plasmid DNA (data not shown). It appears that the two introns in $C m G A S 2$ are at the same locations as the first and third introns of $C m G A S 1$. The intron of $C m G A S 2$ corresponding to the $482 \mathrm{bp}$ intron of $C m G A S 1$ is missing. The three exons of CmGAS2 are $312 \mathrm{bp}, 459 \mathrm{bp}$, and $228 \mathrm{bp}$, and are thought to encode a putative protein 333 amino acids long (Fig. 3B).

GaLACTINOL SYNTHASE EXPRESSION IN MELON. Since the zucchini conserved GAS probe recognized both $C m G A S 1$ and $C m G A S 2$ genes as well as a soybean seed GAS gene (data not shown), it was used as a probe to determine which melon tissues expressed galactinol synthase.

Using the $C p G A S 1$ probe, we did not detect GAS transcript in total RNA extracted from 10- or 21-d seeds, immature (sink) leaves, roots, or mature fruit flesh (Fig. 4). The conserved $C p G A S 1$ probe as well as $C m G A S 1$ and $C m G A S 2$ gene specific probes hybridized strongly to total RNA extracted from mature leaves, and bound to mesophyll/epidermal total RNA to a lesser degree (Fig. 5). Since these mesophyll/epidermal samples were collected by gently scraping buffer-soaked leaves, some vein contamination may be present in the mature mesophyll/epidermal tissue samples.

RNA gel blots made from total RNA extracted from whole mature leaf tissue at 3-h intervals throughout the 16-h light and 6-h dark daily cycle exhibited no dramatic flux in diurnal expression patterns of galactinol synthase transcripts (data not shown).

Early in melon seed development, glucose and sucrose levels were high (Fig. 6A and B). Field grown melons began to accumulate significant levels of raffinose and stachyose 24 DAP, just before the time of maximum dry matter accumulation (Fig. 6A and C). Galactinol synthase transcript was detected in poly $(\mathrm{A})^{+} \mathrm{RNA}$ extracted from seeds $39 \mathrm{DAP}$ when probed with the conserved GAS probe as well with the CmGAS1 gene specific probe (Fig. 7). The results indicate that $C m G A S 1$ is expressed in seeds.

Our northern blot assessment of GAS gene expression in seeds was confirmed with RACE-PCR. This technique is more sensitive than northern blotting and can detect low copy numbers of RNAs. Polymerase chain reaction primers specific to $C m G A S 1$ were synthesized (Table 1) and used in conjunction with an adapted ligated primer (from SMART RACE kit, Clontech) to retrieve cDNAs made from poly (A) ${ }^{+}$RNA extracted from 39 DAP melon seeds. Only the CmGAS1 3' and 5' gene specific primers amplified fragments of melon seed cDNA that hybridized to the conserved GAS probe. Amplified PCR fragments were cloned, sequenced, and determined to be identical to the $C m G A S 1$ gene over the one third of the coding region that was cloned. Thus, $\mathrm{CmGASl}$ is expressed in developing melon seeds. These

Fig. 3. Restriction map of CmGAS1 (A) and CmGAS2 (B) genes. CmGAS1 has 4 exons while $C m G A S 2$ contains 3 exons. 


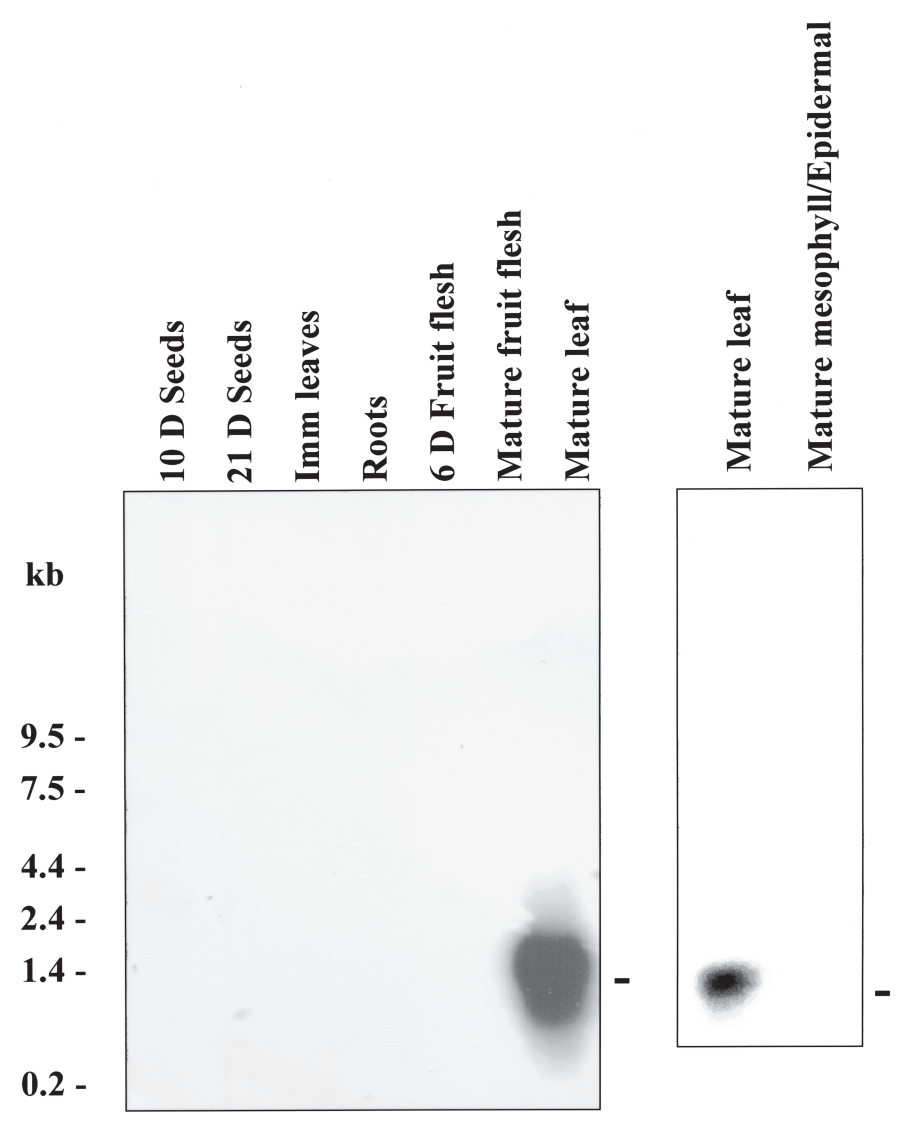

Fig. 4. RNA gel blot analysis of GAS gene expression in melon. Poly(A+)RNA (5 $\mu \mathrm{g}$ ) was extracted from seeds (10 DAP and $21 \mathrm{DAP})$, immature leaves, roots, fruit flesh (6DAP and mature) and $1 \mu \mathrm{g}$ total RNA from mature leaves were hybridized with the $C p G A S 1$ probe. The same probe was used for hybridization with blots made from $5 \mu \mathrm{g}$ of total RNA extracted from mature leaf total and mesophyll/ epidermal tissue samples. GAS mRNA expected size $(\approx 1300 \mathrm{bp})$ is marked.

results confirmed those obtained by RNA gel blot analysis using poly $(\mathrm{A})^{+}$RNA isolated from melon seeds 39 DAP.

GALACTINOL SYNTHASE EXPRESSION IN RESPONSE TO STRESS. There was no change in mature leaf GAS gene expression either 3 or $9 \mathrm{~h}$ after plants were chilled during the dark period. Galactinol synthase gene expression in the leaves of water-stressed melon plants also did not change in response to 4 (nonwilted) or $8 \mathrm{~d}$ (wilted) of water stress. No hybridization was evident in RNA gel blots made from total RNA extracted from roots and immature leaves of these stressed plants (data not shown).

The CmGAS1 promoter analysis reveals the presence of a sequence that may encode a G box (CACGTG) 2885 bases before the putative $C m G A S 1$ translational start site. The CmGAS1 promoter also contains motifs that are present in some phloem specific promoters (ANNNGATA, CCA/TGG). The promoter of CmGAS2 has not been sequenced.

Galactinol Synthase Phylogenetic analyses. While the phylogenetic analyses suggest similar groupings of GAS gene family members based on known expression patterns of genes, strong correlations between sequence similarity and gene function cannot be determined since the expression patterns of GAS gene family members are not fully characterized (Fig. 8). As would be expected, CpGAS1 cDNA and CmGAS1 are very similar. It is also interesting to note that the orthologs AtGolS2, Thellungiella, and AtGolS3 may all be expressed in response to stress conditions.

\section{Discussion}

Galactinol SYNThaSe genes in MELON. We identified two GAS genes in melon. No additional GAS gene family members in either genomic or subgenomic libraries were found. Although future work may reveal the presence of additional gene family members, the $C m G A S 1$ and $C m G A S 2$ genes do exhibit expression patterns consistent with our knowledge of RFO formation in melon.

In cucurbits, raffinose and stachyose serve as translocation sugars and also accumulate in developing seeds. Since the location and function of RFOs are diverse, one might expect each member of the GAS gene family to be expressed for a unique physiological purpose. However, there is some overlap in $C m G A S 1$ and $C m G A S 2$ expression patterns. The roles of the GAS genes are not as specific as the GolS-1 and GolS-2 Ajuga genes: GolS-1 is expressed at a low level in leaves, and its expression increases significantly in response to chilling stress; GolS-2 is expressed in veins and is thought to catalyze the formation galactinol to be used in the synthesis of higher order RFOs for translocation (Sprenger and Keller, 2000).

Both CmGAS1 and CmGAS2 RNAs are expressed in mature leaf tissue. The presence of transcript for the $G A S$ gene is not surprising since galactinol is a key substrate for the formation of the raffinose and stachyose that are translocated in the phloem. We detected a low level of CmGAS1 and CmGAS2 transcript in our mesophyll/epidermal tissue RNA preparations. Since the transcript level was much higher in RNA from total leaf tissue than in mesophyll/epidermal samples, even through veins constitute only a small fraction $(4.5 \%)$ of total cell volume, most of the CmGAS1 and CmGAS2 gene

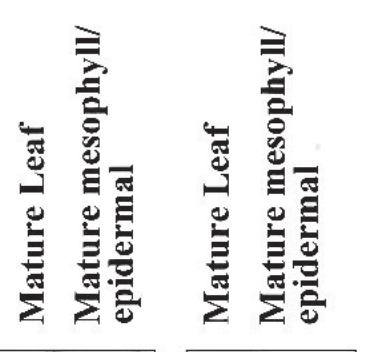
expression clearly occurs within the veins of the mature leaf. Including the veins in RNA samples significantly enhances GAS expression. Phloem specific promoter elements are present within the CmGAS1 promoter and may affect its expression.

Our mesophyll/epidermalcellsamplingtechnique was not ideal. Leaves were immersed in extraction buffer, and the adaxial surfacewaslightly scraped with sandpaper.Itisplausiblethat some intermediary cells wererupturedin the process of sampling; however, it is doubtful that gene expressionpatterns werealtered as aresult of our scraping tech-

Fig. 5. RNA gel blot analysis of total RNA $(5 \mu \mathrm{g})$ extracted from entire mature melon leaf tissue and mesophyll/epidermal tissue samples frommature leaves. Blots were hybridized with either the CmGAS1 or CmGAS2 gene specific probes. Expected GAS gene size is marked. Ethidiumstained nuclear ribosomal RNAs (25S and 18S) are shown below blots. 

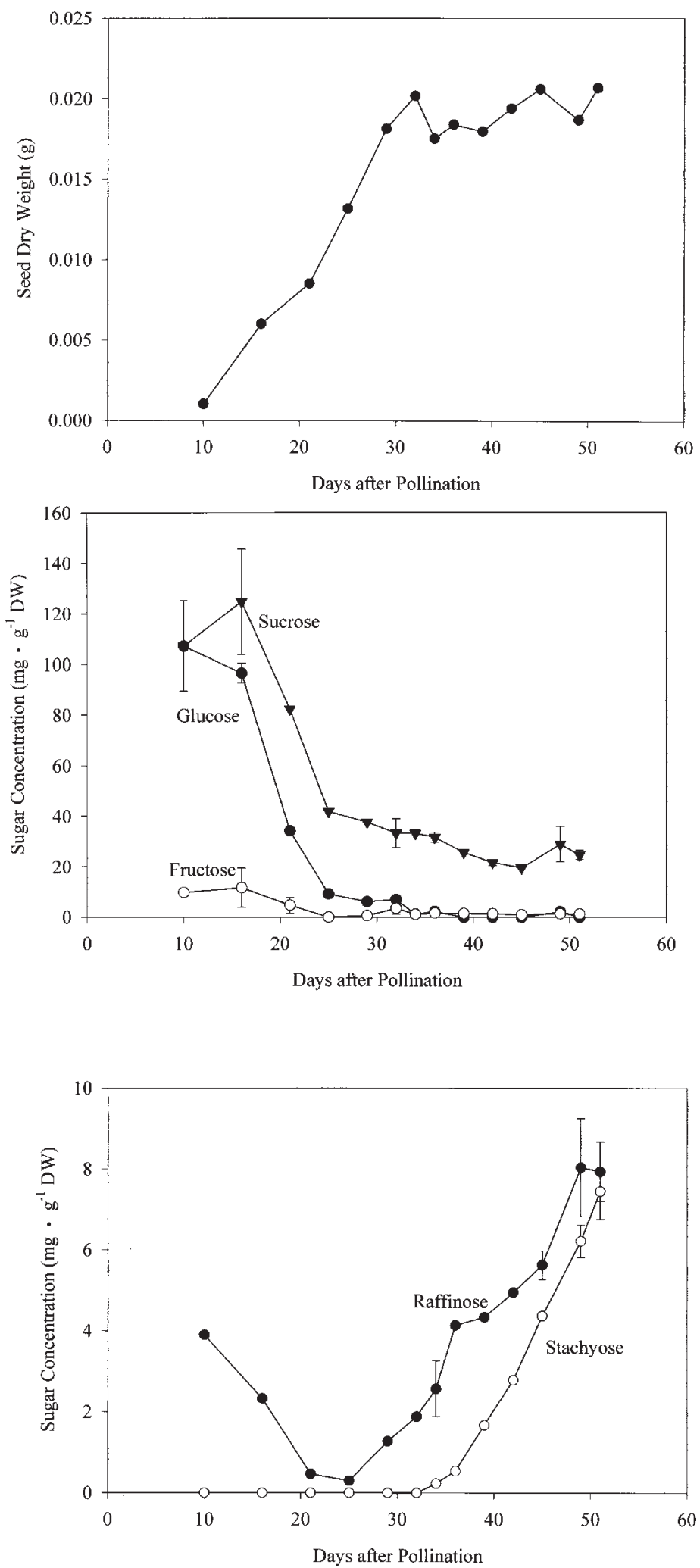

nique since tissues were immersed in extraction buffer during this process. Relative to the entire leaf sample, the mesophyll/epidermal scraping sample was enriched with regard to mesophyll cells, but may also contain some vein contamination. If in fact the observed expression of $C m G A S 1$ and $C m G A S 2$ gene expression in the epidermal/ mesophyll tissues is real, it is most likely even lower than that detected in our samples.

In the minor veins of melon leaves, stachyose and raffinose
Fig. 6. (A) Average individual seed dry weight from melon fruit harvested between 10 and $52 \mathrm{~d}$ after pollination. (B) Sucrose, glucose, and fructose concentration (mean \pm standard error) from three replicate melon fruit. (C) Raffinose and stachyose concentration (mean \pm standard error) from three replicate melon fruit.

accumulate to levels of 330 and $70 \mathrm{~mm}$, respectively; however, the mesophyll concentration of these sugars is less than $1 \mathrm{~mm}$ (Haritatos et al., 1996) and polyclonal antibodies that recognize galactinol synthase and stachyose synthase have been localized to minor vein intermediary cells in cucurbits (Beebe and Turgeon, 1992; Holthaus and Schmitz, 1991). Since galactinol synthase and stachyose synthase are both present in intermediary cells, it is likely that galactinol is formed and subsequently converted to raffinose and stachyose within intermediary cells before its entry into the sieve elements. Sucrose, the precursor to galactinol, could diffuse into intermediary cells via the numerous plasmodesmata at the intermediary cellbundle sheath cell interface. Since stachyose and raffinose are both larger than sucrose, they may not be able to diffuse into the mesophyll through plasmodesmata. Galactinol, however, is approximately the same size as sucrose. According to this previously described polymer-trap model, it would be expected that galactinol would diffuse out of the intermediary cells via plasmodesmata; this may explain in part why the concentration of galactinol (assuming compartmentation) is the same in the cytoplasm of both intermediary cells and mesophyll cells (Haritatos et al., 1996).

Although mesophyll protoplasts isolated from Cucumis melo had no stachyose or stachyose synthase activity in one study (Schmitz and Holthaus 1986), other labs have published evidence that stachyose is synthesized in the mesophyll (Hendrix, 1982; Madore et al., 1988; Madore and Webb, 1982; Madore and Webb, 1981). In immunolocalization studies using a polyclonal GAS antibody, there was no detectable signal above background in the mesophyll (Beebe and Turgeon, 1992). Since gene-specific antibodies to CmGAS1 and CmGAS2 have not been generated, we are unable to determine the specific localization patterns of the GAS genes within melon leaves. Haritatos et al. (2000) succeeded in localizing GUS expression to the veins of tobacco and Arabidopsis when expression was directed by the CmGAS1 promoter, thus providing further evidence that GAS gene expression is highly vein specific.

The significance or the extent of galactinol formation in melon mesophyll cells is not known; however, RFOs do accumulate in the mesophyll cells of low temperature tolerant Ajuga reptans and drought tolerant Xerosicyos danguyi; both translocate RFOs (Bachmann and Keller, 1995; Madore et al., 1988). In the CAM cucurbit, Xerosicyos, galactinol synthase activity was detected in leaf disks made from mesophyll cells (Madore et al., 1988). The RFO biosynthetic pathways may be present in both the intermediary cells of the phloem and in the mesophyll cells in some species (such as Ajuga and Xerosicyos); the purpose of mesophyll RFO metabolism in other crops (such as melon) may be very limited.

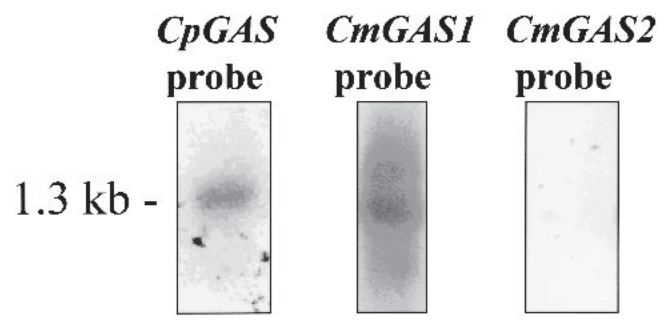

Fig. 7. RNA gel blot analysis using Poly $\left(\mathrm{A}^{+}\right) \mathrm{RNA}(5 \mu \mathrm{g})$ extracted from melon seeds $39 \mathrm{~d}$ after pollination. Blots were hybridized to the $C p G A S 1$ probe, CmGAS1 or CmGAS2 gene-specific probes. 
In mature melon leaves, there is no diurnal fluctuation in GAS transcript level. This is in agreement with our data that show that the relative concentrations of stachyose, raffinose, sucrose and hexoses in mature melon leaves do not fluctuate during the 16-h light period (data not shown). Melon accumulates starch within mesophyll chloroplasts, and may convert this stored carbohydrate to translocatable sugars as needed during the diurnal cycle.

GALACTINOL SYNTHASE EXPRESSION IN SEEDS. We documented the formation of sugars in field-grown melons to ensure that the seeds we collected were actively accumulating RFOs. In these plants, translocated RFOs are hydrolyzed in the fruit and are resynthesized in the seeds. The CmGAS1 transcript is present in melon seeds, where raffinose and stachyose accumulate during the maturation stage of seed development.

The RFOs also accumulate in soybean seeds; a system characterized to a much greater extent than in melon. Raffinose and stachyose begin to accumulate as seeds achieve maximum dry weight(Obendorf et al., 1998; Lowell and Kuo, 1989; Blackman et al., 1992). Sucrose, stachyose, and raffinose in a ratio of 8:4:1 compose $99 \%$ of the soluble sugars in mature soybean seeds (Saravitz et al., 1987) and GAS enzyme activity is high during the time in which RFOs accumulate (Kuo et al., 1997). Saravitz et al. (1987) compared four soybean genotypes which differed in RFO content at maturity. A linear relationship was found between the RFO concentration and galactinol synthase activity. Based on their results, it was hypothesized that galactinol synthesis may be a rate limiting step in the formation of soybean seed RFOs. When most developing orthodox seeds achieve physiological maturity, they undergo a programmed desiccation phase and even low levels of RFOs could alleviate some of the cellular damage induced by extremely low water conditions. If seeds are removed from the plant after RFOs have accumulated to an adequate degree, they remain viable after rapid desiccation (Blackman et al., 1992).

GALACTINOL SYNTHASE EXPRESSION IN RESPONSE TO STRESS. GAS transcript levels were not altered in total RNA extracted from roots, immature leaves, or mature leaves from melon plants after exposure to our low temperature or water stress conditions. This confirms the observation of Mitchell et al. (1992) in which there was no increase in stachyose or other galactosyl oligosaccharides in Cucumis melo after $72 \mathrm{~h}$ of $10^{\circ} \mathrm{C}$ treatment.

Other species do exhibit a cold-acclimation response with regard to GAS gene expression. Kidney bean (Phaseolus vulgaris) leaves, which have no galactinol synthase expression when grown at $27{ }^{\circ} \mathrm{C}$, exhibit galactinol synthase enzyme activity after one to four hours of $4{ }^{\circ} \mathrm{C}$ exposure (Castillo et al., 1990). Bachmann and Keller (1995) determined that $10 \mathrm{~d}$ at a temperature regime of $10 /$ $3{ }^{\circ} \mathrm{C}$ causes a 10 - to 20 -fold increase in Ajuga leaf RFO content. Arabidopsis vegetative tissues (and siliques to a lesser extent) also exhibit a transient increase in galactinol synthase expression during and immediately af- ter low temperature treatment (Liu et al., 1998). Sugar analyses and northern blot analyses in Arabidopsis demonstrated that drought, high salinity, and low temperatures induce GAS gene expression in Arabidopsis. The AtGolS1 and AtGolS2 transcripts were induced by drought and high salinity and AtGolS3 was induced by low temperature stress (Taji et al., 2002).

In our studies, there was no repeatable increase in GAS gene expression either 0,3 , or $9 \mathrm{~h}$ after $8^{\circ} \mathrm{C}$ exposure for 2 or $11 \mathrm{~h}$. Perhaps a temperature of $8{ }^{\circ} \mathrm{C}$ was not adequate to induce GAS gene expression in melon.

The AtGolS1, AtGolS2, and AtGolS3 genes all contain DRE (TACCGACAT), DRE-like (CCGAC), ABRE (CACGTGGC), or ABRE-like (CACGTG, G-box) motifs within promoter regions. Sequence analysis of the $C m G A S 1$ promoter reveals a G-box motif. G-box binding factors may respond to a number of environmental cues including light or hormones (such as ABA) (Siberil et al., 2001).

Although oligosaccharides may play a key role in allowing

Fig. 8. cDNA sequences of GAS gene family members were aligned and subjected to parsimony analysis after removing the first 143 nucleotides (according to the alignment). Support for this clade was estimated by bootstrapping (10,000 replications).

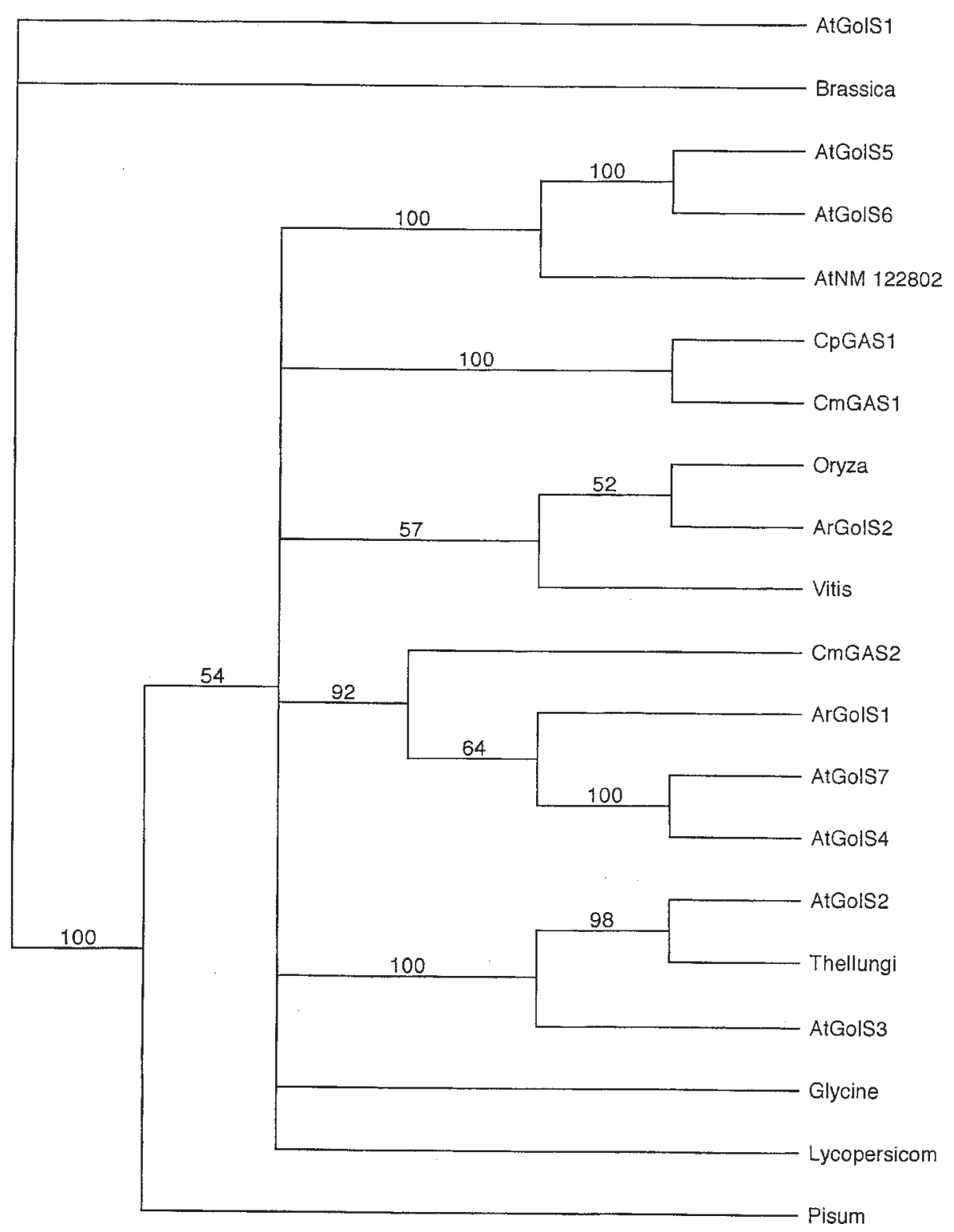


plants to tolerate desiccation, we did not observe an increase in GAS transcription as a result of drought stress in melon. Similarly, Pattanagul and Madore (1999) reported that in coleus (Coleus blumei Benth.), galactinol synthase activity and RFO metabolism were actually depressed by drought stress. Since both of these species translocate significant quantities of RFOs under nonstress conditions, additional synthesis may not be required for protection.

\section{Conclusion}

We have identified two members of the GAS gene family in melon. We were only able to identify GAS gene expression in mature leaves and seeds. The $C m G A S 1$ gene was expressed in seeds as well as in mature leaves whereas $C m G A S 2$ was expressed in mature leaf tissue. Phloem loading is most likely the primary function of RFOs in melon leaves while GAS expression in seeds is probably beneficial for survival after desiccation.

\section{Literature Cited}

Albini, F.M, C. Murelli, P.V. Finzi, M. Ferrarotti, B. Cantoni, S. Puliga, and C. Vazzana. 1999. Galactinol in the leaves of the resurrection plant Boea hygroscopica. Phytochemistry 51:499-505.

Bachmann, M. and F. Keller. 1995. Metabolism of the raffinose family oligosaccharides in leaves of Ajuga reptans L. Inter- and intracellular compartmentation. Plant Physiol. 109:991-998.

Bachmann, M., P. Matile, and F. Keller. 1994. Metabolism of the raffinose family oligosaccharides in leaves of Ajuga reptans L. Plant Physiol. 105:1335-1345.

Beebe, D.U. and R. Turgeon. 1992. Localization of galactinol, raffinose and stachyose synthesis in Cucurbita pepo leaves. Planta 188:354361.

Blackman, S.A., R.L. Obendorf, and A.C. Leopold. 1992. Maturation proteins and sugars in desiccation tolerance of developing soybean seeds. Plant Physiol. 100:225-230.

Caffrey, M., V. Fonseca, and A.C. Leopold. 1988. Lipid-sugar interactions relevance to anhydrous biology. Plant Physiol. 86:754-758.

Castillo, E.M., B.O. de Lumen, B.O, P.S. Reyes, and H.Z. de Lumen. 1990. Raffinose synthase and galactinol synthase in developing seeds and leaves of legumes. J. Agric. Food Chem. 38:351-355.

Castonguay, Y. and P. Nadeau. 1998. Enzymatic control of soluble carbohydrate accumulation in cold-acclimated crowns of alfalfa. Crop Sci. 38:1183-1189.

Corbineau, F., M.A. Picard, J.-A. Fougereux, F. Ladonne, and D. Come. 2000. Effects of dehydration conditions on desiccation tolerance of developing pea seeds as related to oligosaccharide content and cell membrane properties. Seed. Sci. Res. 10:329-339.

Goldsbrough, P.B., S.B. Gelvin, and B.A. Larkins. 1986. Expression of maize zein genes in transformed sunflower cells. Mol. Gen. Genet. 202:374-381.

Haritatos, E., B. G. Ayre, and R. Turgeon. 2000. Identification of phloem involved in assimilate loading in leaves by the activity of the galactinol synthase promoter. Plant Physiol. 123:929-937.

Haritatos, E., F. Keller, and R. Turgeon. 1996. Raffinose oligosaccharide concentrations measured in individual cell and tissue types in Cucumis melo L. leaves: Implications for phloem loading. Planta 198:614-622.

Hendrix, J.E. 1982. Sugar translocation in two members of the Cucurbitaceae. Plant Sci. Lett. 25:1-7.

Holthaus, U. and K. Schmitz. 1991. Distribution and immunolocalization of stachyose synthase in Cucumis melo L. Planta 185:479-486.

Kerr, P.S., R.W. Pearstein, M.F. Becker-Manley and J.W. Pierce. 1993. Nucleotide sequences of galactinol synthase from zucchini and soybean, p. 1-78. International Patent Publ. No. WO 93/02196, 4 Feb. 1993, PCT/US92/06057.

Kirby, K.S. and E.S. Cook. 1967. Isolation of deoxyribonucleic acid from mammalian tissues. Biochem. J. 104:254-257.

Kuo, T.M., C.A. Lowell, and T.C. Nelsen. 1997. Occurrence of pinitol in developing soybean seed tissues. Phytochemistry 45:29-35.

Liu, J. J., D.C. Krenz, A.F. Galvez, and B.O. de Lumen. 1998. Galactinol synthase (GS): Increased enzyme activity and levels of mRNA due to cold and desiccation. Plant Sci. 134:11-20.

Lowell, C.A. and T.M. Kuo. 1989. Oligosaccharide metabolism and accumulation in developing soybean seeds. Crop Sci. 29:459-465.

Madore, M.A, D.E. Mitchell, and C.M. Boyd. 1988. Stachyose synthesis in source leaf tissues of the CAM plant Xerosicyos danguyi H. Humb. Plant Physiol. 87:588-591.

Madore, M. and J.A. Webb. 1981. Leaf free space analysis and vein loading in Cucurbita pepo. Can. J. Bot. 59:2550-2557.

Madore, M. and J.A. Webb. 1982. Stachyose synthesis in isolated mesophyll cells of Cucurbita pepo. Can. J. Bot. 60:126-130.

McMaster, G.K. and G.G. Carmichael. 1977. Analysis of single- and double-stranded nucleic acids on polyacrylamide and agarose gels by using glyoxyl and acridine orange. Proc. Natl. Acad. Sci. 74:48354838 .

Mitchell, D.E., M.V. Gadus, and M.A. Madore. 1992. Patterns of assimilate production and translocation in muskmelon Cucumis melo L. I. Diurnal patterns. Plant Physiol. 99:959-965.

Muller, J., N. Springer, K. Bortilk, T. Boller, and A. Wiemken. 1997. Desiccation increases sucrose levels in Ramonda and Haberlea, two genera of resurrection plants in the Gesneriaceae. Physiol. Plant. 100:153-158.

Obendorf, R.L, M. Horbowicz, A.M. Dickerman, P. Brenec, and M.E. Smith. 1998. Soluble oligosaccharides and galactosyl cyclitols in maturing soybean seeds in planta and in vitro. Crop Sci. 38:78-84.

Pattanagul, W. and M.A. Madore. 1999. Water deficit effects on raffinose family oligosaccharide metabolism in Coleus. Plant Physiol. 121:987-993.

Peterbauer, T. and A. Richter. 2001. Biochemistry and physiology of raffinose family oligosaccharides and galactosyl cyclitols in seeds. Seed Sci. Res. 11:185-197.

Sambrook, D.M., E.F. Fritsch, and T. Maniatis. 1989. Molecular cloning. A laboratory manual. Cold spring Laboratory Press, Cold Spring Harbor, N.Y.

Saravitz, D.M., D.M. Pharr, and T.E.J. Carter. 1987. Galactinol synthase activity and soluble sugars in developing seeds of four soybean genotypes. Plant Physiol. 83:185-189.

Schmitz, K. and U. Holthaus. 1986. Are sucrosyl-oligosaccharides synthesized in mesophyll protoplasts of mature leaves of Cucumis melo? Planta. 169:529-535.

Siberil, Y., P. Doireau, and P. Gantet. 2001. Plant bZIP G-box binding factors-Modular structure and activation mechanisms. Euro. J. Biochem. 268:5655-5666.

Sprenger, N. and F. Keller. 2000. Allocation of raffinose family oligosaccharides to transport and storage pools in Ajuga reptans: The roles of two distinct galactinol synthases. Plant J. 21:249-258.

Swofford, D. 2002 PAUP*. Phylogenetic analysis using parsimony (*and other methods). Version 4. Sinauer Associates, Sunderland, Mass.

Taji, T., C. Ohsumi, S. Iuchi, M. Seki, M. Kasuga, M. Kobayashi, K. Yamaguchi-Shinozaki, and K. Shinozaki. 2002. Important roles of drought- and cold-inducible genes for galactinol synthase stress tolerance in Arabidopsis thaliana. Plant J. 29:417-426.

Turgeon, R. 1991. Symplastic phloem loading and the sink-source transition in leaves: A model, p. 18-22. In: J.L. Bonnemain, S. Delrot, J. Dainty, and W.J. Lucas (eds.). Proc. 1990 Intl. Conf. Phloem Transport and Assimilate Compartmentation. Ouest Editions, Nantes, France.

Turgeon, R., D.U. Beebe, and E. Gowan. 1993. The intermediary cell: Minor vein anatomy and raffinose oligosaccharide synthesis in the scrophulariaceae. Planta 191:446-456.

Turgeon, R., R. Medville, and K.C. Nixon. 2001. The evolution of minor vein phloem and phloem loading. Amer. J. Bot. 88:1331-1339.

Zimmerman, M.H and H.Ziegler. 1975. List of sugars and sugar alcohols in sieve-tube exudates, p. 480-503. In: M.H. Zimmerman and J.A. Milburn (eds.). Transport in plants: Phloem transport. Springer, New York. 